\title{
El modelo de aprendizaje basado en casos clínicos
}

El razonamiento clínico constituye la piedra angular de la práctica médica asistencial y, por ello, resulta fundamental la promoción de competencias dirigidas a perfeccionar su enseñanza'. El aprendizaje basado en casos clínicos supone una herramienta muy atractiva y formativa a este respecto, tanto en el período de residencia como durante el resto de la vida profesional como médico.

En la década de 1980, la Organización Mundial de la Salud (OMS) promovió el desarrollo de nuevos enfoques educativos en la formación de profesionales de la Medicina, orientados y dirigidos al fomento de la formación participativa centrada en el estudiante'. De esta forma, el eje de los esfuerzos educativos en materia médica pasó del tradicional modelo pedagógico -que entiende al alumno como receptor pasivo en la transmisión del conocimiento por parte del docente (modelo flexneriano)- a una pedagogía de tipo constructivista -que propicia una actitud proactiva por parte del estudiante para la elaboración de conocimientos con la supervisión del docente'.

Se ha evidenciado en los últimos años que los diferentes sistemas y métodos de formación basados en el razonamiento clínico resultan muy efectivos y, como consecuencia, se ha impuesto y difundido ampliamente un aprendizaje sustentado en casos clínicos ${ }^{2}$. No obstante, el desequilibrio entre la labor asistencial y el tiempo disponible para las actividades formativas provoca dificultades para dedicar tiempo a estas últimas y, en cierta medida, insatisfacción entre los profesionales sanitarios ${ }^{1,2}$. En el lado opuesto, están los estudiantes de Medicina, quienes comúnmente se forman mediante la impartición de talleres, seminarios, reuniones clínicas o encuentros simulados que, en ocasiones, no continúa durante el posgrado ${ }^{1,3}$. Por este motivo, se produce un desfase en la formación continuada difícil de corregir, y que requiere la búsqueda y utilización de recursos que favorezcan la formación acompasada con la labor asistencial. En esta línea, los casos clínicos y su análisis constituyen un pilar en la formación de los profesionales de la salud, tanto en el período pre como posgrado, al inferir enseñanzas médicas desde la práctica clínica.

Al exponer y discutir casos clínicos, se instruye en las habilidades necesarias de razonamiento analítico, al dar capacidad de elaborar un diagnóstico por problemas basado en la interpretación y recolección secuencial de datos y en el reconocimiento de patrones de enfermedad ${ }^{1,4}$. De esta manera, la lectura y el análisis de casos clínicos contribuyen al entrenamiento de los futuros profe- sionales, con la creación de una red de conocimientos que se organiza progresivamente, según aumenta la experiencia médica, y que permite dibujar una representación del problema, sintetizar los datos en los diferentes síndromes clínicos y adoptar medidas precisas para abordar un caso ${ }^{4}$. Así pues, el modelo de aprendizaje basado en casos clínicos constituye una herramienta con alto poder formativo en todas las etapas de la vida profesional como médico, siendo un complemento estratégico para afianzar la integración del conocimiento y complementar la asistencia diaria con la docencia médica.

Además, en la actualidad, se acrecienta la preocupación sobre la seguridad de los pacientes, por lo que se idean nuevas estrategias educativas frente a los errores médicos, dentro de la llamada "medicina defensiva"s. Por ello, en los últimos años, han surgido diversos espacios supervisores, como el Espacio Europeo de Educación Superior, que velan por la calidad de la educación superior y que se fundamentan en la Medicina Basada en la Evidencia en la enseñanza médica ${ }^{5}$. Esto explica que cada vez haya un mayor interés en el aprendizaje y abordaje clínico por problemas como guía de buena práctica médica, con la discusión de casos clínicos como aliado en esta formación.

La discusión de casos clínicos sitúa al médico en diferentes entornos, pudiendo entrenarse también en el método de la prueba y el error, y, con ello, practicar y aprender en un entorno de seguridad "ficticio" que ayuda a evitar los potenciales riesgos del entrenamiento directo con el paciente ${ }^{5}$. El objetivo, en última instancia, es lograr la solución de un problema de salud mediante las habilidades y competencias conseguidas a través del entrenamiento adquirido con las discusiones de casos clínicos simulados o reales. Esto hace que los casos clínicos sean un método pedagógico fundamental en la enseñanza de la Medicina, al ser su discusión una forma atractiva, motivadora y participativa para los estudiantes en la resolución de problemas y aproximación al entorno real de su profesión ${ }^{1,5}$.

Como conclusión, enfrentarse a situaciones simuladas o reales a través de la lectura y discusión de casos clínicos potencia la enseñanza médica a través del entrenamiento en el pensamiento crítico por problemas, $y$, además, por la escenificación asistencial, ejercita a los profesionales sanitarios en la adecuada toma de decisiones y en la actuación óptima ante diferentes situaciones clínicas de su vida profesional.

\section{Francisco Javier de Jorge-García-Reyes \\ Francisco Javier de Jorge-García-Reyes
ad Complutense de Madrid. Madrid. España}

jjorge@buc.ucm.es

Lucía de Jorge-Huerta Jefa de Residentes 2020-2021. Facultativo Especialista. Medicina Interna. Hospital Universitario 12 de Octubre. Madrid. España

Citar como: de-Jorge-García-Reyes FJ, de-Jorge-Huerta L. El modelo de aprendizaje basado en casos clínicos. Rev Esp Casos Clin Med Intern (RECCMI). 2020 (Ago); 5(2): 57-59. doi: 10.32818/reccmi.a5n2a1.

Cite this as: de-Jorge-García-Reyes FJ, de-Jorge-Huerta L. The clinical case-based learning model. Rev Esp Casos Clin Med Intern (RECCMI). 2020 (Ago); 5(2): 57-59. doi: x10.32818/reccmi.a5n2a1. 


\section{Bibliografía}

1. Ferreira Bacciarini J. Enseñanza de razonamiento clínico a residentes de Medicina Interna mediante un modelo de aprendizaje basado en casos. Educ Med. 2019; 20(S2): 67-73. doi: 10.1016/j.edumed.2018.03.021.

2. Thistlethwaite JE, Davies D, Ekeocha S, Kidd J, MacDougall C, Matthews $P_{\text {, }}$ et al. The effectiveness of case based learning in health professional education. A BEME systematic review: BEME Guide N. ${ }^{2}$ 23. Med Teach. 2012; 34 e421-444. doi: 10.3109/0142159X.2012.680939.

3. Ramani S, Leinster S. AMEE Guide no. 34: Teaching in the clinical environment. Med Teach. 2008; 30(4): 347-364. doi: 10.1080/01421590802061613.
4. Durante E. La enseñanza en el ambiente clínico: principios y métodos. REDU. Revista de Docencia Universitaria. 2012; 10(ne): 149-175.

5. Serrano-Gámez N, Bermúdez-Garcell A, Solís-Cartas U, Teruel-Ginés R, Leyva-Montero MA, Bermúdez-Serrano A. Utilidad de la discusión de casos clínicos en la enseñanza de pregrado de los estudiantes de Medicina. Rev Cuba Reumatol (Internet). 2017; 19(Suppl1): 235-241. Disponible en: http://scielo. sld.cu/scielo.php?script=sci_arttext\&pid=\$1817-59962017000400013\&lng=es (citado 2020 Jul 17). 